\title{
Study on Adoption of Eco-Friendly Management Practices by Vegetable Growers in Indore Block of Indore District (M.P.)
}

\author{
Ms.Neerja Patel * Dr. Sandhya Choudhary** \& Dr. V. K. Swarnakar*** \\ *M.Sc. Extension Education Final Year Student 2013 \\ **Associate Professor Extension Education, College of Agriculture, Indore \\ *** Professor \& Head Extension Education, College of Agriculture, Indore
}

\begin{abstract}
The development of India is depending on agriculture and it is engaging about 70 per cent of its population directly or indirectly. It contributes nearly 37 per cent of the net national product and account for a sizable share of total value of the country's export. The present rate of agriculture production could be doubled if the available technology is appropriately transferred to the farmers for its adoption. It is however reported that not more than 30 to 40 per cent of the technologies have gone to the farming communities so far, even though there is strong network of extension mechanism operating for accelerating agriculture production. The study was conducted in Indore Block of Indore District with 120 vegetable growers of 10 villages which were selected randomly and considered for study on the basis of larger area coverage. Maximum vegetable growers had low extent of adoption of the eco-friendly management practices followed by medium and high extent of adoption of the eco-friendly management practices respectively.

Keywords- Eco-friendly farming, Ecological balance, Agrochemical, Sustainable farming
\end{abstract}

\section{Introduction}

Eco-friendly and environmentally friendly are synonyms used to refer to goods and services considered to inflict minimum or no harm on the environment. To make consumers aware environmentally friendly goods and services often are marked with eco-labels. Eco-friendly farming is the process of producing food naturally. This method avoids the use of synthetic chemicals and generally modified organisms to influence the growth of crops. The main idea behind eco-friendly farming is Zero impact on environment. It works in harmony with nature rather than against it. This involves musing techniques to achieve good crop yields without harming the natural environment or the people who live and work in it.

This type of farming is a production system which avoids or largely excludes the use of synthetically compounded fertilizers, growth regulators and live stock feed additives. To the maximum extent, feasible ecofriendly farming systems rely on crop rotations, crop residues, animal manures, legumes, green manures, off farm organic wastes and aspects of biological pest control to maintain soil productivity and tilth to supply plant nutrients and to control insect-pests diseases and weeds. Thus, the eco-friendly farming implies recycling of waste and residue to the native soil itself, replenishing the nutrients depleted from the soil during the crop growth, encouraging the growth of microorganisms which could regulates phased release of stored nutrients in the soil to the crop growth in right proportion, maintaining soil health by balancing the soil moisture and soil aeration and ensuring soil fertility by firmly binding the nutrient elements in the complex organic molecules.

The important eco-friendly technologies worthy of mentioning are organic farming, natural farming, traditional farming, sustainable farming, bio-dynamic and pharmaculture, which may be all together considered as eco-friendly farming.

Indiscriminate use of high analysis fertilizers has caused several problems on farm as well as outside farm. Plants become more susceptible to pests and diseases and their control could be effectively done by using high potency poisonous chemicals. As a result, their residue on plants and in the soil had lead to health hazards (Malathi and Bangarusamy, 2001). Similarly, excess nitrogen as nitrate and phosphate leached through the soil and entered natural sources of drinking water also responsible for health hazards. The chemical detrimental effects of fertilizers in plants are reduction in germination, retardation in seedling growth, scorching and increased susceptibility to diseases (Asha et al., 2001).

The Less Intensive Farming Environment (LIFE) has already shown that the use of chemicals in farming can be substantially cut without loss of profit. Thus, eco-friendly technologies promise a great hope for minimizing the chemical hazards and restoration of ecological balance.

The modern agriculture has been successful in meeting the increased food needs of alarmingly growing population. But, the problem associated with modern agriculture like, the high cost of inorganic or chemical fertilizers and plant protection chemicals, stagnated yield levels. Over the years and the mounting health and environmental hazards have forced many farmers and scientists to focus attention on ecologically sound, viable and sustainable alternative non-chemical farming. In order to mitigate these health hazards and bring out natural 
balance and protection of ecosystem, organic movement has started in several parts of the world, in which no chemical fertilizers and plant protection chemicals are used in the cultivation of field crops, vegetables and fruits. It is ascertained that the indiscriminate use of agro-chemicals and pesticides cause adverse changes in the ecological balance.

\section{Objective of study:}

1) To find out the extent of adoption of eco-friendly management practices by vegetable growers.

\section{Review Of Literature}

Bhople et al. (2001) revealed that 81.33 per cent farmers belonged to low adoption category of farmers of bio-control pest management practices is concerned in cotton, followed by 16.67 and 2.00 per cent of them belonged to medium and high adoption categories, respectively.

Darling and Vashanthakumara (2004) indicated that more than half respondents were found with low level of adoption, medium (43.44\%) level regarding adoption of botanical pesticides.

Shashidhara et al. (2006) conducted a study and find out the extent of adoption of eco-friendly management practices by vegetable growers, revealed that majority of the respondents were in medium level adoption of eco-friendly technologies. With respect to adoption on integrated nutrient management, majority of the respondents were not adopting the technologies viz., application of organic manures, selection of crops and cropping pattern, mixed cropping, inter cultivation practices, application of bio-fertilizers to soil and use of optimum inorganic fertilizers.

Raj et al. (2009) conducted a study in Keonjhar district of Orissa and revealed that poor knowledge and adoption of good variety, soil, seed \& seedling treatment, fertilizer management with use of micronutrient, plant protection measures and post harvest operation were observed with the vegetable growers.

Sasane et al. (2010) revealed that almost all brinjal growers were complete adoption about selection of soil and preparatory tillage. Majority of growers had complete adoption about intercultural operations (93.34 per cent), irrigation management (92.20 per cent), harvesting (89.17 per cent), nursery management (42.50 per cent), fertilizer management (35.00 per cent), transplanting (52.50 per cent).

\section{RESEARCH METHODOLOGY}

The study was conducted in Indore block of Indore district (M P). In the study the sample were drawn through application of multi stage sampling method. Indore district comprises of four blocks out of which only block, namely Indore was selected purposively because, the block has maximum area under vegetable cultivation and near to Agriculture University. The total number of vegetable grower's villages in block was 161.Out of which 10 villages were selected randomly. A list of vegetable growers of 10 selected villages was prepared with the help of RHEO/RAEO. Out of which an equal number of growers were selected through random sampling method to make the total sample size of 120 for investigation.

The data were collected personally with the help of a pre-tested interview schedule. The interview schedule was designed for collecting the relevant information of selected variables. All the respondents had answered the questions fully, which was indicative of the fact that good rapport could be established between the investigator and respondents. After establishing rapport with the respondents they were interviewed and their responses recorded in interview schedule, for analysis of data.

\section{Result \& Discussion}

Extent of adoption of eco-friendly management practices by vegetable growers.

The finding of the study clearly shows that there was less percentage of respondents who had complete adoption practices of eco-friendly management practices by the vegetable growers. Higher percentage of farmers partially adopted the simple practices like field preparation, seed rate, sowing time and method, manures and fertilizers management and irrigation management, while as regard to complex practices, majority of the farmers had low adoption of disease management, weed management, insect and pest control. The data clearly indicates that the high gap may be due to nature of the particular technology and poor extension services in the area. The practices which contributed major part of the gap were precaution in using chemicals, insectdisease control and seed treatment practices which require careful attention of extension workers through making appropriate extension strategies for grass root level. The finding is similar to the work of Bhople et al. (2001), Darling and Vashanthakumara (2004), Patel, G.P. (2007), Pyasi et al. (2009). 
Table 1.0

\begin{tabular}{|c|l|l|l|c|c|}
\hline $\begin{array}{c}\text { S. } \\
\text { No }\end{array}$ & \multicolumn{1}{|c|}{ Variables } & $\chi^{2}$ Value & $\begin{array}{l}\text { Association with } \\
\text { adoption }\end{array}$ & $\begin{array}{l}\text { Degree of } \\
\text { freedom }\end{array}$ & $\begin{array}{l}\text { Level of } \\
\text { probability }\end{array}$ \\
\hline 1. & Age & $\chi^{2}=11.783$ & Significant & 4 d.f & 0.05 \\
\hline 2. & Annual income & $\chi^{2}=10.93$ & Significant & 4 d.f & 0.05 \\
\hline 3. & Socio-economic status & $\chi^{2}=14.29$ & Significant & 4 d.f & 0.01 \\
\hline 4. & Economic motivation & $\chi^{2}=12.28$ & Significant & 4 d.f & 0.05 \\
\hline 5. & $\begin{array}{l}\text { Attitude towards use of eco- } \\
\text { friendly management practices }\end{array}$ & $\chi^{2}=14.83$ & Significant & 4 d.f & 0.05 \\
\hline 6. & Marketing orientation & $\chi^{2}=7.268$ & Non-significant & 4 d.f & 0.05 \\
\hline 7. & $\begin{array}{l}\text { Knowledge about eco- } \\
\text { friendly management practices }\end{array}$ & $\chi^{2}=16.28$ & Significant & 4 d.f & 0.01 \\
\hline 8. & \multicolumn{1}{|c|}{ Mass media exposure } & $\chi^{2}=13.39$ & Significant & 4 d.f & 0.01 \\
\hline 9. & Extension participation & $\chi^{2}=10.42$ & Significant & 4 d.f & 0.05 \\
\hline 10 & $\begin{array}{l}\text { Information seeking } \\
\text { behaviour }\end{array}$ & $\chi^{2}=13.78$ & Significant & 4 d.f & 0.01 \\
\hline
\end{tabular}

\section{Association between attributes of vegetable growers with their adoption of eco-friendly management practices}

Maximum respondents were from middle age group (59.17\%) having low annual income (60.83\%) and medium socio economic status (63.33\%), having medium economic motivation (58.33 per cent), had favourable attitude towards the use of eco-friendly management practices $(59.16 \%)$, having low marketing orientation (52.50\%), having low knowledge of the eco-friendly management practices (85.83\%), having low mass media exposure $(62.50 \%)$, medium extension participation $(52.50 \%)$ with medium information seeking behaviour (81.66\%) and low extent of adoption of the eco-friendly management practices (68.33\%).

Significant association was found between age, annual income, socio economic status, economic motivation, attitude towards use of eco-friendly management practices, knowledge level, mass media exposure, extension participation, information seeking behaviour with adoption of the eco-friendly management practices of the vegetable growers and non significant association was found between marketing orientation with adoption of the eco-friendly management practices of the vegetable growers.

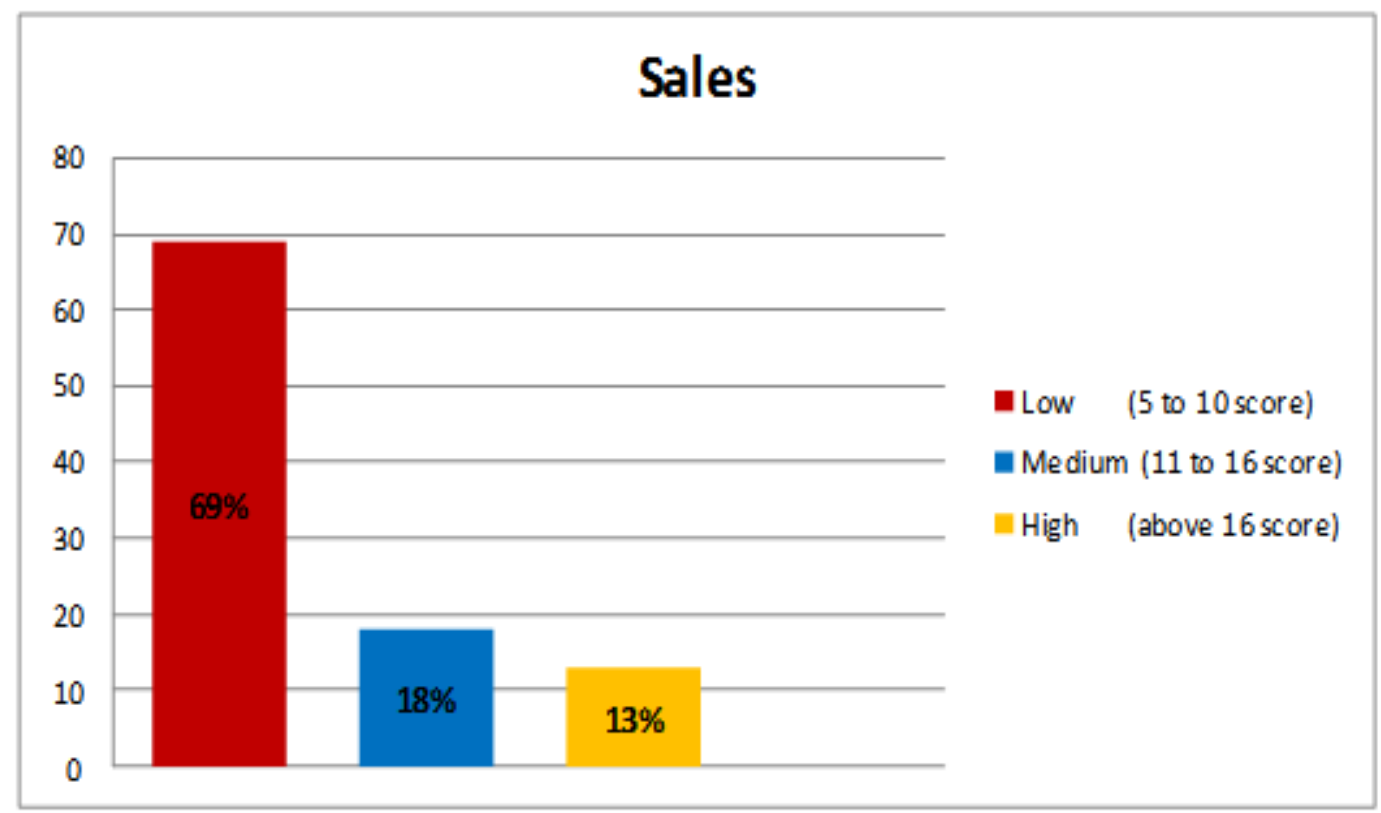

Fig.1: Distribution of respondents according to their adoption of the eco-friendly management practices IMPLICATIONS

The findings of this investigation are very much useful in creating awareness amongst the farmers to reduce ill effect and use of agro-chemicals in agriculture. The study reveals importance of adopting eco-friendly management practices in order to increase vegetable production in the field and the result of study is important for the progressive vegetable growers because by this study they can overcome the constraints 
and adopt eco-friendly management practices for better production. This study helps to provide more exposure to the vegetable growers adopting eco-friendly management practices.

\section{References}

[1] Asha, K.R., M. Ameena and V.L. Geetha Kumari (2001) Excessive use of chemical fertilizers harmful. Kisan World, 28(9): 36-37.

[2] Bhople, R.S., P.S. Shinde and S.S. Dhule (2001) Knowledge and adoption of bio-control pest management in cotton. Maharashtra Journal of Extension Education, 20:18-21.

[3] Darling, B. Suji and J. Vasanthakumar (2004) Knowledge and adoption of botanical pesticides, Journal of Extension Education, 15(2\&3): 3655-3658.

[4] Malathi, D. and U. Bangarusamy, (2001) Harmful effects of agricultural chemicals. Agro-India Handbook on Food processing. R. K. Business International, Bangalore, pp .232-235.

[5] Patel, G.P. (2007) A study on adoption of organic farming technology among the farmers of selected block of Damoh District (M.P.). M.Sc. (Ag.)Thesis, JNKVV, Jabalpur.

[6] Pyasi, R. D, Aparna Jaiswal and Chaurasaia, P. C. (2009) Adoption of eco-friendly management practices by vegetable growers. Journal of Plant Development Sciences; 2012. 4: 1, 77-80. 12 ref.

[7] Raj, R. K., L. Pradhan, Ray, P. and M. Behera (2009) Vegetables cultivation - grower's knowledge and adoption of management practices. Journal of Interacademicia; 2009. 13: 4, 501-506. 3 ref.

[8] Sasane, G. K., U. D. Jagdale, and R. P. Khule (2010) Knowledge and adoption of brinjal management practices by the farmers. Agriculture Update; 2010. 5: 3/4, 495-497. 3 ref.

[9] Shashidhara, K. K. and L. Manjunath (2008) Adoption of eco-friendly management practices by vegetable growers of North Karnataka. International Journal of Agricultural Sciences; 2008. 4: 2, 480-484. 3 ref. 